СУТОЧНОЕ ИЗМЕНЕНИЕ

СТРУКТУРЫ И ФИЗИЧЕСКИХ ХАРАКТЕРИСТИК ГРУПП ПЯТЕН НА ВИДИМОМ ДИСКЕ СОЛНЦА

\author{
Голубчина О.А. ${ }^{1}$, Топчило Н.А. ${ }^{2}$ \\ ${ }^{1}$ Санкт-Петербургский филиал САО РАН, Санкт-Петербург, Россия \\ ${ }^{2}$ Санкт-Петербургский Государственный Университет, Санкт-Петербург, Россия
}

\title{
DAILY CHANGE OF STRUCTURE AND PHYSICAL CHARACTERISTICS OF GROUPS OF SPOTS ON A VISIBLE DISK OF THE SUN
}

Golubchina O.A. ${ }^{1}$, Topchilo N.A. ${ }^{2}$

${ }^{I}$ SAO RAS, St. Petersburg St. Petersburg branch, Russia

${ }^{2}$ St. Petersburg State University, St. Petersburg, Russia

According to observations on the radio telescope RATAN-600 on 9,10.02.1980 of year the unusual phenomenon of daily reduction of the polarized radiation and magnetic-field strength of the majority of the local sources of centimetric radiation identified with groups of spots on the photosphere of the Sun is registered. According to observations of the Kislovodsk Station of the Pulkovo Observatory and the Ussuri Station daily disintegration of these sunspot groups located in both hemispheres of the Sun is registered. The comparative analysis of daily evolution of characteristics of a radio emission of local sources and the sunspot groups corresponding to them is provided.

\section{DOI: 10.31725/0552-5829-2018-111-114}

Теория возникновения и распада солнечных пятен рассмотрена в ряде работ как «концепция первичного поля» [1], «пятно типа спагетти» [2], «взаимодействие магнитного поля и супергрануляционной сетки» $[3,4]$. Согласно этим работам образование солнечных пятен связано с выходом магнитных трубок на поверхность Солнца. Распад солнечных пятен обусловлен либо раскручиванием жгута солнечных магнитных трубок, либо «возобновлением ранее подавленного движения супергранул» [5]. Наблюдение радиоизлучения Солнца в сантиметровом диапазоне длин волн на РАТАН-600 и наблюдение в белом свете, выполненное на ГАС ГАО, позволили получить некоторые новые наблюдательные данные об эволюции групп солнечных пятен на стадии распада. Наблюдение сантиметрового радиоизлучения Солнца выполнено на РАТАН-600 9,10.02.1980 г. в двух режимах: в режиме «эстафета» на Северо-Восточном секторе $(\lambda=2.3 \mathrm{~cm})$ [6] и в «штатном» режиме [7] на Южном секторе с перископом $(\lambda=2.7 \mathrm{~cm}$, 4.0 см). В режиме «эстафета» наблюдения выполнены в течение трёх часов с интервалом между последовательными прохождениями Солнца через диаграмму направленности антенны $\Delta \mathrm{t}=20$ мин. В «штатном» режиме в эти дни выполнены одноразовые наблюдения в меридиане. Размер гори- 
зонтальной $\left(\rho_{\Gamma}\right)$ и вертикальной $\left(\rho_{\text {в }}\right)$ диаграммы направленности антенны в режиме «эстафеты» на $\lambda=2.3$ см: $\rho_{\text {г }}$ (угл. мин. $)=1.1, \rho_{\text {в }}($ угл. мин. $)=15.4$. В «штатном» режиме: $\lambda=2.7 \mathrm{~cm}, \rho_{г}$ (угл. сек.) $=25, \rho_{\text {в }}($ угл. мин.) $=22.2$; $\lambda=4.0 \mathrm{cм}, \rho_{г}$ (угл. сек.) $=38, \rho_{\text {в }}$ (угл. мин.) $=33$.

Площади восьми групп пятен, расположенных на видимом диске Солнца, №№: 54, 55, 63,69,71, 72, 74, 66 составляли $\mathrm{S}=(72-1390)$ м.д.П. Угловые размеры ( $)$ исследуемых локальных источников (л.и.), отождествлённых с этими группами пятен, на $\lambda=2.3$ см: $\rho=(1.0-2.5)$ угл. мин., радиопотоки: $\mathrm{F}=(0.5-3.0)$ с.е.п. Величины относительных потоков л.и., отождествлённых с группами пятен №№ (ц.69, г.п.69, 72+74), составляют $\mathrm{F}_{\text {и }} \mathrm{F}_{\odot}=(0.9-2.4) \%$. Обозначения локальных источников: ц.69 - л.и. центра группы №69, г.п.69 - л.и. головного пятна группы №69, 72+74 - л.и., отождествлённый соответственно с группами №72 и №74; Ги - поток выделенного л.и., $\mathrm{F}_{\odot}$ - поток радиоизлучения выделенного спокойного Солнца. Запись Солнца в канале поляризации 10.02.1980 г. заметно упростилась по сравнению с записью Солнца 9.02.1980 г. Амплитуды сигналов радиоизлучения л.и. в канале поляризации 10.02.1980 г. либо значительно уменьшились, либо источники радиоизлучения совсем исчезли, кроме радиоизлучения л.и. (г.п.69) (рис. 1).

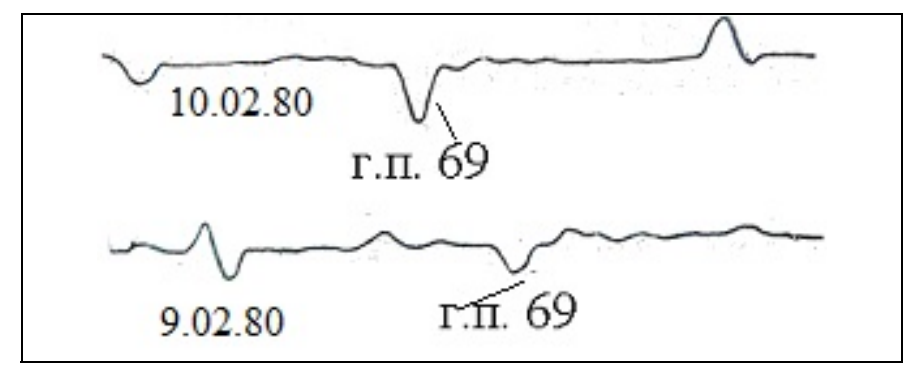

Рис.1.Упрощение записи поляризованного радиоизлучения Солнца на волне 2.3 см с 9.02. на 10.02.1980 г.
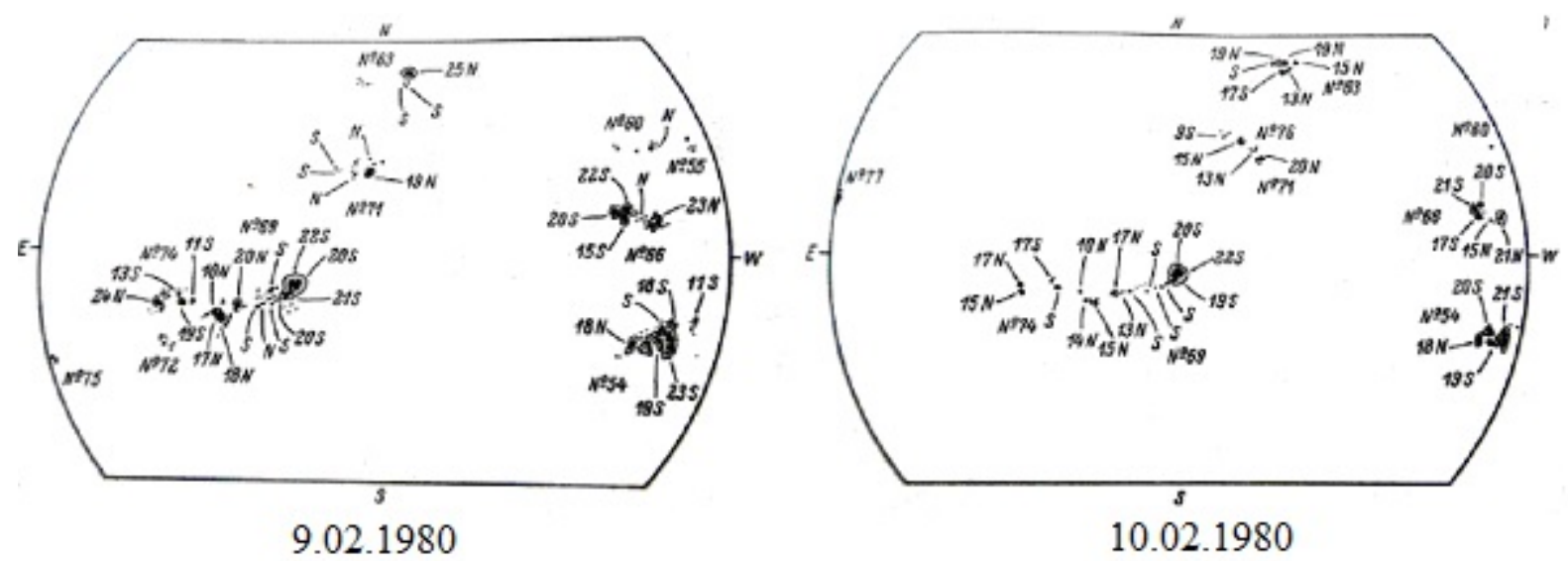

Рис.2. Карты магнитных полей солнечных пятен и изменения структуры групп пятен с 9 на 10 февраля 1980 по данным Кисловодской станции ГАС ГАО РАН (Солнечные данные. Бюллетень № 2, 1980 г.) 
По данным ГАС ГАО и Уссурийской станции на фотосфере Солнца 10.02.1980 г. наблюдалась более простая конфигурация всех групп пятен (рис. 2). В ряде групп ведущие пятна разделились на несколько отдельных пятен. Также наблюдалось исчезновение одного из отделившихся пятен (г.п.69) [8]. Для анализа динамики поляризованного излучения локальных источников определялись степени поляризации - $\mathrm{P}(\%)$ и величины магнитных полей $-\mathrm{B}(\Gamma \mathrm{c})$ по формулам: $\lambda=2.3 \mathrm{~cm}, \mathrm{P}(\%)=[\mathrm{Tv} /(2 * \mathrm{Ti})] * 100 \%$, где Tv, Ti - антенные температуры на записи выделенных локальных источников в канале поляризации и в канале интенсивности соответственно (табл. 1). На волнах 2.7 см и 4.0 см: Р (\%) = [Sv/(2*Si)] * 100\%, где $\mathrm{Sv}, \mathrm{Si}-$ площади на записи под выделенными локальными источниками в канале поляризации и в канале интенсивности соответственно (табл. 1).

Таблица 1. Степени поляризации радиоизлучения локальных источников (л.и.) Солнца $(\mathrm{P}, \%)$ и значения напряжённости магнитных полей В (Гс) исследуемых (л.и.), отождествлённых с соответствующими группами пятен на фотосфере Солнца $(\mathrm{L}, \mathrm{R}-$ левая и правая поляризации).

\begin{tabular}{|c|c|c|c|c|c|}
\hline \multirow{2}{*}{$\begin{array}{c}\text { «эстафета» } \\
\lambda=2.3 \mathrm{~cm}\end{array}$} & \multicolumn{5}{|c|}{ № группы (канал поляризации) } \\
\hline & 69(г.п.) & 69(центр) & $72+74$ & 71 & 63 \\
\hline $\begin{array}{c}09.02 .1980 \\
(\mathrm{P}, \%)\end{array}$ & $47 \mathrm{~L}$ & $4.9 \mathrm{R}, 3.3 \mathrm{~L}$ & $7.7 \mathrm{R}, 4.2 \mathrm{~L}$ & $11.0 \mathrm{~L}, 16.5 \mathrm{R}$ & $27 \mathrm{R}$ \\
\hline $\begin{array}{c}10.02 .1980 \\
(\mathrm{P}, \%)\end{array}$ & $79 \mathrm{~L}$ & $2.4 \mathrm{R}, 6.0 \mathrm{R}$ & $4.6 \mathrm{R}$ & $7.8 \mathrm{~L}, 5.1 \mathrm{R}$ & $10.2 \mathrm{R}$ \\
\hline \multirow{2}{*}{$\begin{array}{c}\text { «эстафета» } \\
\lambda=2.3 \mathrm{~cm}\end{array}$} & \multicolumn{5}{|c|}{ № группы (канал поляризации) } \\
\hline & 69(г.П.) & 69(центр) & $72+74$ & 71 & 63 \\
\hline $\begin{array}{c}09.02 .1980 \\
\text { В(Гc) }\end{array}$ & $1104 \mathrm{~L}$ & $114 \mathrm{R}, 77 \mathrm{~L}$ & $179 \mathrm{R}, 104 \mathrm{~L}$ & $255 \mathrm{~L}, 383 \mathrm{R}$ & $628 \mathrm{R}$ \\
\hline $\begin{array}{c}10.02 .1980 \\
\mathrm{~B}(\Gamma \mathrm{c})\end{array}$ & $1552 \mathrm{~L}$ & $56 \mathrm{R}, 130 \mathrm{~L}$ & $107 \mathrm{R}$ & $181 \mathrm{~L}, 118 \mathrm{R}$ & $237 \mathrm{R}$ \\
\hline
\end{tabular}

Степень поляризации л.и. (г.п. 69) за сутки $(9,10.02 .1980$ г.) значительно увеличилась: на $\lambda=2.3$ см от $\mathrm{P}(\%)=47$ до $\mathrm{P}(\%)=79$, на $\lambda=2.7 \mathrm{~cm}$ от $\mathrm{P}(\%)=37$ до $\mathrm{P}(\%)=100, \lambda=4.0$ см от $\mathrm{P}(\%)=48$ до $\mathrm{P}(\%)=100$. Степени поляризации остальных локальных источников низкие (1.4-16)\% и, как правило, к 10.02.80 г. уменьшились (табл. 1).

Результаты вычислений величин магнитных полей приведены в табл. 1. Величины магнитных полей локальных источников магнитотормозного (теплового) механизма излучения не превышают нескольких сотен гауссов и уменьшаются с 9.02.80 г. на 10.02.80 г. Максимальные величины магнитных полей крупных пятен в исследуемых группах пятен на фотосфере Солнца уменьшились за сутки (рис. 2).

Исследуемые наблюдения Солнца в сантиметровом диапазоне длин волн и в белом свете выявили уменьшение степени поляризации локаль- 
ных источников, величины магнитного поля л.и., уменьшение максимальных значений величин магнитного поля крупных пятен исследуемых групп, отделение части пятна от основного пятна и исчезновение пятен. Обращает на себя внимание тот факт, что этот процесс произошёл за одни сутки во всех группах пятен, расположенных в обоих полушариях Солнца. Возможной причиной такой глобальной перестройки структуры групп пятен является действие единого подфотосферного источника.

\section{Основные выводы}

1. С 9.02. на 10.02.1980 г. на фотосфере Солнца наблюдалось резкое изменение и упрощение структуры семи групп пятен, расположенных по всему диску Солнца и одновременное ослабление или исчезновение поляризованного излучения большинства локальных источников.

2. Степень поляризации и напряжённость магнитного поля локального источника (г.п.69) циклотронного механизма излучения резко возросли за сутки с 9.02 на 10.02.80 г.

3. Резкое изменение напряжённости магнитного поля локальных источников радиоизлучения и упрощение структуры соответствующих групп пятен на фотосфере Солнца, возможно, связано с изменением подфотосферного магнитного поля, общего для всех рассмотренных групп пятен под действием единого подфотосферного источника.

\section{Литература}

1. Piddington J.H. // Astrophys. And Space Sci., 1975, v.34, p.347.

2. Parker E.N. // Astrophys. J., 1978, v. 222, p. 357.

3. Meyer F., Schmidt H.U., Weiss N.O.,Wilson P.R. // Mon. Notic. Roy. Astron. Soc., 1974, v. 169, p.35,.

4. Пономаренко Ю.Б. // АЖ, 1970, т. 47, с.98.

5. Обридко В.Н. Солнечные пятна и комплексы активности - Издательство «Наука», 1985.

6. Golubchina O.A., Golubchin G.S. // Astrofiz. Issled. (Izv.Spets. Astrofiz. Obs.), 1981, No.14, p.125.

7. Гиндилис Л.М., Есепкина Н.А., Кардашёв Н.С. // Изв. ГАО, 1972, № 188, с. 54.

8. Солнечные данные. 1980, № 2. 